\title{
MULTI-OBJECTIVE INTEGRATED PRODUCTION PLANNING MODEL AND SIMULATION CONSTRAINED DOUBLY BY RESOURCES AND MATERIALS
}

\author{
Wang, C. ${ }^{* * *}$; Liu, X.-B. ; Zhao, G.-Z. ${ }^{*} \&$ Chin, K. O. ${ }^{* * *}$ \\ ${ }^{*}$ School of Business Administration, Dalian University of Technology, Dalian 116024, P. R. China \\ ${ }^{* *}$ School of Economics and Management, Qiqihar University, Qiqihar 161006, P. R. China \\ ${ }^{* * *}$ School of Engineering \& Information Technology, University Malaysia Sabah, Sabah 88400, \\ Malaysia \\ E-Mail: wangcheng_dalian@126.com
}

\begin{abstract}
Based on analysing the defects of ERP planning system and researching related literatures, a multiobjective integrated production planning model is constructed which is constrained doubly by resources and materials. The model takes delivery on-time, reduces inventory, reduces overtime work, maintains safety inventory as its optimization objectives, and can achieve the integrated optimization of production planning, material requirements planning, resource requirements planning, inventory planning and overtime work planning. We build a mixed integer programming model and use Lingo to complete the model solution and simulation analysis, the case shows that the optimization method provided by the model has strong feasibility and effectiveness.

(Received, processed and accepted by the Chinese Representative Office.)
\end{abstract}

Key Words: Integrated Production Planning, Multi-Objective Optimization, Optimization Model, Resources, Materials, Simulation

\section{INTRODUCTION}

Planning is the primary function in manufacturing enterprises, which is the order to arrange and coordinate the operating for the whole manufacturing enterprises. Only have strong planning function, can the manufacturing enterprises be guide the production and business operation activities smoothly. ERP (Enterprise Resource Planning) is one of the most popular resource management and control system, which originated in MRP (Material Requirements Planning) and has become main system of many manufacturing enterprises for enhancing competitive advantage, efficiency, and performance of modern organization's business process [1]. Now more and more manufacturing enterprises use ERP system to schedule and manage resources uniformly and have achieved some success. However, it is difficult for the production planning module to satisfy the actual requirements of schedule and management, which affects the performance of ERP system in a certain extent [2]. The reason is mainly due to that the planning system of ERP lack an overall optimization mechanism. In that condition, the main production planning, material requirements planning, capacity requirements planning and other plans of the planning system need to be calculated separately, and the Coordination of multi-level plans is completed manually. The planning system can't give the overall optimized schedule automatically. In addition, only material and capacity are put into considerations to determine whether it is reasonable to make the production planning arrangements, but other performance management objectives in the manufacturing process are not brought into the examination scope. In the situation with customers' needs changing rapidly and daily production management getting more and more complicated, the above mentioned disadvantages are getting even more prominent and the conventional ERP planning model cannot adapt the changing needs more and more [3]. 
Against the weakness of ERP system, some papers propose methods to improve the coordination between material requirements planning and capacity requirements planning, and to optimize the planning. The methods are about improving the schedule of lot-size and lead time [4-7], adjusting the work capacity and balance algorithm [8], optimizing the process route [9-10], and so on. But these researches only consider the local optimization or improvement of ERP system, not resolve the problems in ERP system radically. Based on this, some researches propose integrated production planning models and methods to solve the problem of simultaneous optimization of multi-level plans in enterprises. The paper [11] integrates the conception of JIT and TOC into ERP and constructs integrated production planning and control model, but it doesn't give the specific model and algorithm. The paper [12] proposes a resource optimization model of manufacturing enterprise in purpose of high profit. The model is based on supply chain and gives a general mathematical model, but it still needs a more efficient algorithm for large-scale optimization problems. The paper [13] proposes an enterprise resource planning model under the double constraints of lack of operational capacity and available resources limited. This model is based on the bill of manufacturing (BOMII). It gives a heuristic solution procedure. The paper [14] proposes an integrated production planning and control model in the limit of single product, single bill of material and single production resource. It can make the production planning based on the limited capacity in the name of on-time delivery. In the overall optimization of the production-planning system, besides the necessary constraints, it needs to consider the performance and management objectives of the manufacturing process to achieve the multiobjective optimization. The papers [15-18] propose a multi-objective optimization model and algorithm, but the optimization objects are limited to the main production schedule, not including the optimization of the whole plan system.

In general, most studies have been focusing on the defects and disadvantages of the ERP system to carry out partial improvement or optimization, which increase the usability and practicality in certain level for better execution effects. At the same time, studies on the optimization design of planning system as a whole, which have come to a better execution effect, are relatively less. In view of the complication of the management and scheduling of enterprise's resources, there are still no unified, mature and effective solutions in the production scheduling and control.

In this paper, we proposed a multi-objective optimization model of integrated production planning. When making production plan under this model, besides materials and production capacity, it also considers performance objectives of manufacturing process, such as delivery on-time, reducing inventory, reducing overtime work, keeping safety inventory and so on. It will integrate and optimize the production planning, material requirements planning, capacity requirements planning, inventory planning and overtime work planning.

The paper is organized as follows: the next section discusses the multi-objective integrated production planning model, and states the optimization objective and the key problem of the model. Section 3 builds a mixed integer programming model based on the integrated production planning model. Section 4 proposes the model solution and simulation analysis. Conclusions and ideas for future studies are given in section 5.

\section{MULTI-OBJECTIVE INTEGRATED PRODUCTION PLANNING MODEL}

The enterprise's production planning is the guiding scheme to the activities in its planning period. When making the production planning, it should be able to meet the production requirements and the constraints of materials and capacity, at the same time achieve the 
performance objectives of manufacturing process as far as possible. The multi-objective integrated production planning model is shown in Fig. 1.

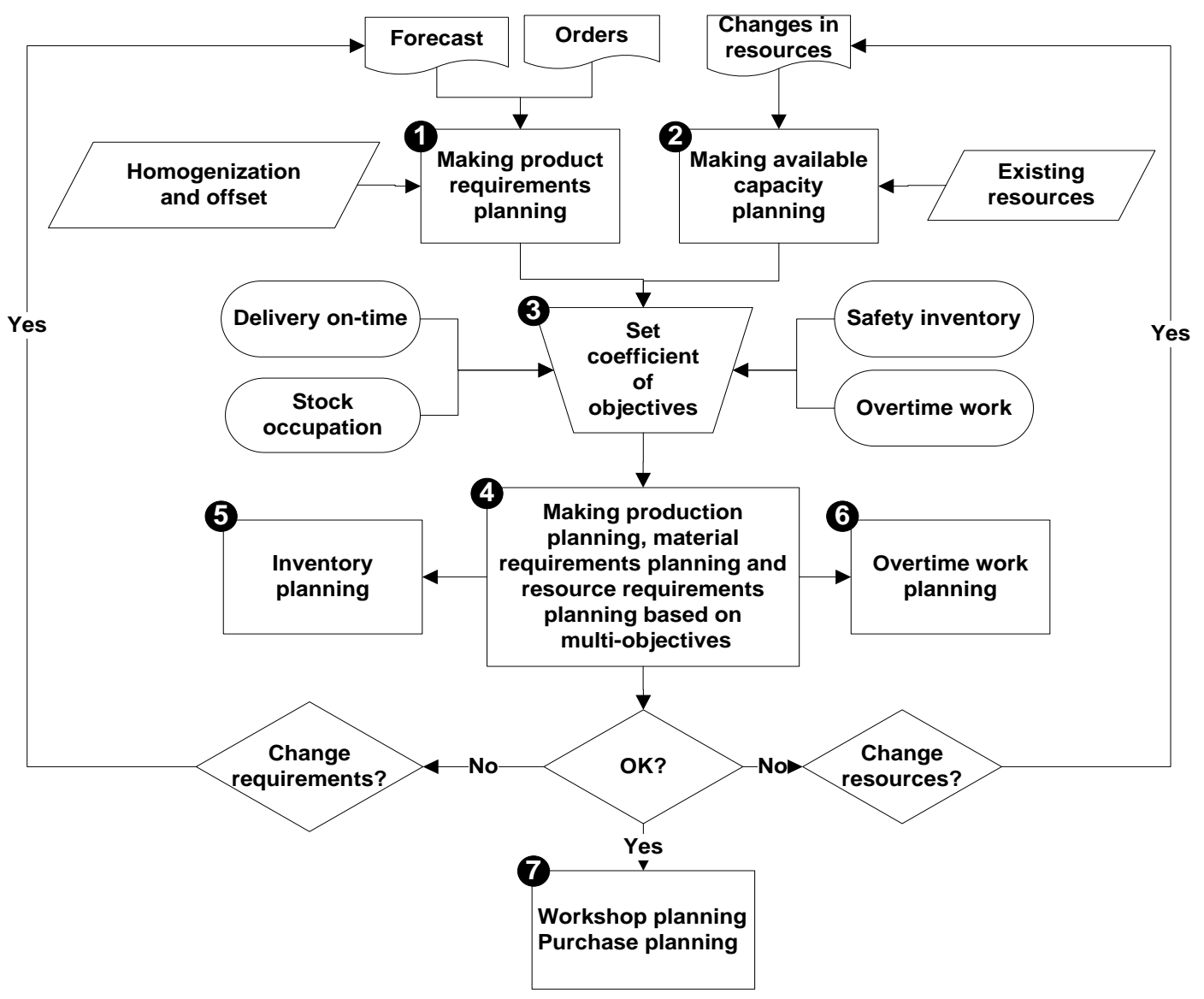

Figure 1: Multi-objective integrated production planning model.

The basic logic of the model is following: Firstly, according to the requirement forecasting and data of orders, considering the rules of homogenization and offset, make the product demand planning $\mathbf{D}$. Secondly, according to the existing resources and their changing condition, make the available capacity planning for products 2 . The available capacity includes available capacity in normal time and overtime. Thirdly, according to the product demand planning and the available capacity planning, considering the 4 performance and management objectives of delivery on-time, stock occupation, overtime work and safety inventory $\mathbf{3}$, make the multi-objective production planning, material requirements planning, resource requirements planning $\boldsymbol{\Phi}$, inventory planning $\boldsymbol{\Theta}$ and overtime work planning $\boldsymbol{0}$. This process can be repeated and it can get different plans by changing the value of the coefficient of each objective. If it can't get a satisfactory plan, we could consider changing the requirements or production capacity. If it gets the satisfactory plan, we will make the following workshop planning and purchase planning then $\boldsymbol{\nabla}$.

\subsection{Optimization objective of the model}

The model mainly have the following four performance and management objectives.

(1) Delivery on-time

Delivery on-time means to deliver the products to customers in accordance with the demanded quantity and quality in required time. It will enhance the reputation of enterprises and the satisfaction of customers. However, under the realistic condition, enterprises can't 
avoid delay in delivery because of the constraints of equipment, human resource, and material etc. The goal of enterprises should be a most minimum delay in delivery.

(2) Stock occupation

Stock occupation refers to the buffer stock of various products and work in process in the production process. It can be seen as an up-front investment for enterprises to satisfy the requirements of customers and the needs of management. This kind of stock will need some funds. From the view of cost, the stock occupation should be as small as possible.

(3) Costs of overtime work

When the capacity in normal time can't meet the requirements of products and material production efficiently, it can use the capacity in overtime work. Overtime work will produce extra costs.

(4) Safety inventory

Safety inventory is an estimated stock to insure preventing from uncertainties. When the existing capacity is not sufficient to solve the contradiction between supply and demand, enterprises could use the safety inventory. When the capacity is sufficient, enterprises will not use the safety inventory generally.

\subsection{The key problem solved}

The multi-objective optimization model of integrated production planning can solve the following key problems.

(1) Make the plan while considering the constraints of materials and capacity. Constraints of materials refer to the restriction of raw material and products in process, which can be calculated by decomposing the bill of material (BOM). Constraints of capacity refer to the limitation of production capacity in enterprises. Considering the characteristics of management of production planning, it can turn the constraints of capacity to constraints of production resources. The constraints of materials and capacity ensure the feasibility of the production planning.

(2) Optimize and control the production planning in the performance and management objectives of delivery on-time, reducing inventory, reducing overtime work, keeping safety inventory and so on. The managers can set objective priority through weight coefficient to choose or abandon objectives of the enterprise. Also, the managers can calculate the weight coefficients of different objectives according to the realistic condition or make decisions based on all the objectives.

(3) Integrate and optimize the production planning, material requirements planning, resource requirements planning, inventory planning, and overtime working planning within the unified framework. It can solve the problems that plans are separating from each other and the coordination needs manual feedback in the traditional ERP system.

(4) Provide effective basis to the following workshop planning and purchase planning. The optimization model considers the constraints of materials and capacity in manufacturing process. Based on this, enterprises can make workshop planning and purchase planning.

\section{MATHEMATICAL MODEL}

Based on the multi-objective optimization model of integrated production planning above, we construct the following mixed integer programming model.

\subsection{Subscript of model}
$i, j$ : material;
$r$ : resource;
$t$ : phase. 


\subsection{Limit of the model subscripts}

$I G$ : integration of products;

$I W$ : integration of intermediate materials;

$I R$ : integration of raw materials;

$I$ : integration of all materials, $I=I G+I W+I R$;

$R$ : integration of resources;

$T$ : integration of total phases.

\subsection{Model parameters}

$T$ : number of phases;

$O H_{i}$ : the inventory of material $i$ at the beginning of phases;

$M A_{t i}$ : the maximum allowable inventory of material $i$ in phase $t$

$S S_{t i}$ : the safety inventory of material $i$ in phase $t$;

$G R_{t i}$ : the gross requirements of material $i$ or product $i$ in phase $t$;

$B S_{t i}$ : the quantity of standard lot-size of material $i$ in phase $t$;

$B O M_{i j}$ : the quantity of material $j$ needed when producing material $i$;

$L T_{i j}$ : the minimum lead time of material $j$ needed when producing material $i$;

$N A C_{t r}$ : the normal capacity of resource $r$ available in phase $t$, expressed in time;

$O A C_{t r}$ : the capacity in overtime works of resource $r$ available in phase $t$; expr. in time;

$U R_{i r}$ : the productivity of material $i$ related to resource $r$, that is the output per time;

$M C_{t i}$ : extra-cost of per material $i$ if it doesn't enough in phase $t$;

$I C_{t i}$ : per inventory cost of material $i$ in phase $t$;

$R C_{t r}$ : per overtime cost of resource $r$ in phase $t$;

$S C_{t i}$ : the extra-cost of material $i$ when it is under the safety inventory in phase $t$.

\subsection{Model variables}

$B I_{t i}$ : the inventory of material $i$ at the beginning of phase $t$;

$E I_{t i}$ : the inventory of material $i$ at the end of phase $t$;

$A I L_{t i}$ : the average inventory of material $i$ in phase $t$;

$T A C_{t r}$ : the total capacity of resource $r$ available in phase $t$, expressed in time;

$T C U_{t r}$ : the total used capacity of resource $r$ in phase $t$, expressed in time;

$O C U_{t r}$ : the total used capacity in overtime work of resource $r$ in phase $t$, expr. in time;

$G R_{t i}$ : the gross requirements of material $i$ (intermediate materials and raw materials) in phase $t$;

$R N M_{t i}$ : the material $i$ doesn't meet its requirements in phase $t$;

$B N_{\text {tir }}$ : planned batches of material $i$ produced in phase $t$ and related to resource $r$;

$P S_{t i r}$ : planned quantity of material $i$ produced in phase $t$ and related to resource $r$;

$T P S_{t i}$ : planned quantity of material $i$ produced in phase $t$.

\subsection{Objective function}

$$
\begin{gathered}
T C=\min \left(\sum_{\mathrm{t}=1}^{T} \sum_{r=1}^{R}\left(O C U_{t r} * R C_{t r}\right)+\sum_{t=1}^{T} \sum_{i=1}^{I}\left(A I L_{t i} * I C_{t i}\right)+\sum_{\mathrm{t}=1}^{T} \sum_{j=1}^{I G}\left(R N M_{\mathrm{tj}} * M C_{t j}\right)+\right. \\
\left.+\sum_{t=1}^{T} \sum_{i=1}^{I}\left(B S S_{t i} * S C_{t i}\right)\right)
\end{gathered}
$$




\subsection{Constraint equations}

$$
\begin{aligned}
& B I_{t i}=\left\{\begin{array}{ll}
O H_{i} & s e(t=1) \\
E I_{(t-1) i} & s e(t>1)
\end{array} \quad \forall t \in T, i \in I\right. \\
& E I_{t i}=\left\{\begin{array}{l}
\max \left(0, B I_{t i}+T P S_{t i}-G R_{t i}\right), \quad t=1 \\
\max \left(0, B I_{t i}+T P S_{t i}-G R_{t i}-R N M_{(t-1) i}\right), \quad t>1
\end{array} \quad \forall t \in T, i \in I\right. \\
& A I L_{t i}=\left(B I_{t i}+E I_{t i}\right) / 2 \quad \forall t \in T, i \in I \\
& R N M_{t i}=\left\{\begin{array}{l}
\max \left(0, G R_{t i}-B I_{t i}-T P S_{t i}\right), t=1 \\
\max \left(0, R N M_{(t-1) i+} G R_{t i}-B I_{t i}-T P S_{t i}\right), t>1
\end{array} \quad \forall t \in T, i \in I\right. \\
& B I_{t i} \leq M A_{t i} \quad \forall t \in T, i \in I \\
& E I_{t i} \leq M A_{t i} \quad \forall t \in T, i \in I \\
& T P S_{t i}=\sum_{r=1}^{R}\left(P S_{t i r}\right) \quad \forall t \in T, i \in I W \cup I G, r \in R \\
& P S_{t i r}=B N_{t i r} \cdot B S_{t i} \quad \forall t \in T, i \in I W \cup I G, r \in R \\
& G R_{t j}=\sum_{i=1}^{I W \cup I G}\left(T P S_{\left(t+L T_{i j}\right) i} \cdot B O M_{i j}\right) \quad \forall t \in T, j \in I W \cup I R, t+L T_{i j} \quad\left\langle T, \mathrm{BOM}_{\mathrm{ij}}>0\right. \\
& R N M_{t i}=0 \quad \forall t \in T, i \in I W \cup I R \\
& T A C_{t r}=O A C_{t r}+N A C_{t r} \quad \forall t \in T, r \in R \\
& T C U_{t r}=\sum_{i=1}^{I W \cup I G} \frac{P S_{t i r}}{U R_{i r}} \quad \forall t \in T, i \in I W \cup I G, r \in R \\
& T C U_{t r} \quad\left\langle T A C_{t r} \quad \forall t \in T, r \in R\right. \\
& O C U_{t r}=\max \left(0, T C U_{t r}-N A C_{t r}\right) \quad \forall t \in T, r \in R \\
& B S S_{t i}=\max \left(0, S S_{t i}-E I_{t i}\right) \quad \forall t \in T, i \in I \\
& B N_{\text {tir }} \gg 0
\end{aligned}
$$

Constraints description:

(1) Calculate the inventory of materials at the beginning of every phase;

(2) Calculate the inventory of materials at the end of every phase; when calculating, consider the quantity of the lacking materials at the end of last phase;

(3) Calculate the average inventory of materials in every phase;

(4) Calculate the quantity of the lacking materials in every phase;

(5) The constraints of inventory of materials at the beginning of every phase;

(6) The constraints of inventory of materials at the end of every phase;

(7) Calculate the planned quantity of materials produced in every phase;

(8) Calculate the planned quantity of materials produced in every phase and related to every kind of resources;

(9) The planned quantity of materials produced last phase turns to the gross requirements of materials in next phase.

(10) Intermediate materials and raw materials must not be out of stock;

(11) Calculate the total capacity of resources available in every phase;

(12) Calculate the total used capacity;

(13) The constraint of capacity; 
(14) Calculate the using of capacity in overtime work;

(15) Calculate the lacking quantity of materials that below the safety inventory;

(16) The constraint that variable must be non-negative.

\section{CASE AND SIMULATION ANALYSIS}

In this paper, we use Lingo 11.0 to complete the model solution and simulation analysis. Lingo is a kind of special software that can be used to solve the linear programming model, nonlinear programming, and integer optimization. It has characteristics of quick to execute, simple to input and easy to operate etc. It can be used to indicate complicated planning problem, to create and solve the model and to analysis solution.

In order to simplify the process of analysis, we choose two kinds of products, two kinds of intermediate materials, four kinds of raw materials, two kinds of resources and data of ten phases to analysis the process. The basic data is shown in Table I to Table IV.

Table I: BOM of product.

\begin{tabular}{|c|l|c|c|}
\hline Priority & \multicolumn{1}{|c|}{ Name of material } & Quantity & $\begin{array}{c}\text { Lead time (relative to } \\
\text { materials of last process) }\end{array}$ \\
\hline 1 & Product 1 & 1 & 0 \\
\hline 2 & Intermediate material 1 & 2 & 1 \\
\hline 3 & Raw material 1 & 2 & 0 \\
\hline 3 & Raw material 2 & 2 & 1 \\
\hline 2 & Intermediate material 2 & 3 & 1 \\
\hline 3 & Raw material 3 & 1 & 0 \\
\hline 1 & Product 2 & 1 & 0 \\
\hline 2 & Raw material 3 & 1 & 2 \\
\hline 2 & Raw material 4 & 2 & 1 \\
\hline
\end{tabular}

Table II: Information on materials.

\begin{tabular}{|l|c|c|c|c|}
\hline \multicolumn{1}{|c|}{ Name of material } & $\begin{array}{c}\text { Initial } \\
\text { inventory }\end{array}$ & $\begin{array}{c}\text { Maximum } \\
\text { inventory }\end{array}$ & $\begin{array}{c}\text { Safety } \\
\text { inventory }\end{array}$ & $\begin{array}{c}\text { Quantity of standard } \\
\text { lot-size }\end{array}$ \\
\hline Product 1 & 20 & 200 & 10 & 1 \\
\hline Product 2 & 0 & 400 & 20 & 1 \\
\hline Intermediate material 1 & 0 & 800 & 0 & 1 \\
\hline Intermediate material 2 & 0 & 800 & 0 & 1 \\
\hline Raw material 1 & 0 & 400 & 0 & 1 \\
\hline Raw material 2 & 0 & 800 & 0 & 1 \\
\hline Raw material 3 & 0 & 800 & 0 & 1 \\
\hline Raw material 4 & 0 & 400 & 0 & \\
\hline
\end{tabular}

Table III: Product requirements and capacity.

\begin{tabular}{|l|c|c|c|c|c|c|c|c|c|c|c|}
\hline \multirow{2}{*}{ Project } & \multicolumn{10}{|c|}{ Thase } & \multirow{2}{*}{ Total } \\
\cline { 2 - 14 } & 1 & 2 & 3 & 4 & 5 & 6 & 7 & 8 & 9 & 10 & \\
\hline Product 1 requirement & & & 60 & 65 & 25 & 60 & 50 & 35 & 65 & 86 & 446 \\
\hline Product 2 requirement & & & 50 & 116 & 60 & 15 & 58 & 30 & 26 & 80 & 435 \\
\hline Normal capacity of resource 1 & 8 & 8 & 8 & 8 & 8 & 8 & 8 & 8 & 8 & 8 & 80 \\
\hline Overtime capacity of resource 1 & 8 & 8 & 8 & 8 & 8 & 8 & 8 & 8 & 8 & 8 & 80 \\
\hline Normal capacity of resource 2 & 8 & 8 & 8 & 8 & 8 & 8 & 8 & 8 & 8 & 8 & 80 \\
\hline Overtime capacity of resource 2 & 4 & 4 & 4 & 4 & 4 & 4 & 4 & 4 & 4 & 4 & 40 \\
\hline
\end{tabular}


Table IV: Productivity of materials.

\begin{tabular}{|l|c|c|}
\hline Name of material & Resource 1 & Resource 2 \\
\hline Product 1 & 20 & 10 \\
\hline Product 2 & 20 & 10 \\
\hline Intermediate material 1 & 10 & 20 \\
\hline Intermediate material 2 & 20 & 20 \\
\hline
\end{tabular}

In the following, we choose two different cases composed of objectives with different priority to carry out analysis on the purpose of comparison.

(1) Considering delivery on-time, overtime costs and inventory levels by priority

Set $M C_{t i}=10000, R C_{t i}=100, I C_{t r}=1, S C_{t r}=0$, then optimize the schedule by the model, get that: $Z R N M=0, Z O C U=15, Z A I L=854$. The detailed information is shown in Table $\mathrm{V}$ to Table VIII.

Table V: The production schedule of products and intermediate materials related to every resource.

\begin{tabular}{|c|c|c|c|c|c|c|c|c|c|c|c|c|c|c|c|c|c|c|c|c|}
\hline \multirow{4}{*}{$\begin{array}{l}\text { Name of } \\
\text { material }\end{array}$} & \multicolumn{20}{|c|}{ Phase } \\
\hline & \multicolumn{2}{|c|}{1} & \multicolumn{2}{|c|}{2} & \multicolumn{2}{|c|}{3} & \multicolumn{2}{|c|}{4} & \multicolumn{2}{|c|}{5} & \multicolumn{2}{|c|}{6} & \multicolumn{2}{|c|}{7} & \multicolumn{2}{|c|}{8} & \multicolumn{2}{|c|}{9} & \multicolumn{2}{|c|}{10} \\
\hline & reso & urce & resc & urce & reso & Irce & resou & ree & reso & urce & reso & urce & reso & urce & resol & urce & reso & urce & resou & rce \\
\hline & 1 & 2 & 1 & 2 & 1 & 2 & 1 & 2 & 1 & 2 & 1 & 2 & 1 & 2 & 1 & 2 & 1 & 2 & 1 & 2 \\
\hline Product 1 & & & & & 106 & & 44 & & 32 & & 46 & & 52 & & 42 & & 22 & & 80 & 2 \\
\hline Product 2 & & & & & 50 & & 116 & & 60 & & 15 & & 58 & & 56 & & & & 80 & \\
\hline $\begin{array}{c}\text { Intermediate } \\
\text { material } 1\end{array}$ & & & 52 & 160 & & 88 & & 64 & & 92 & & 104 & & 84 & & 156 & & 52 & & \\
\hline $\begin{array}{c}\text { Intermediate } \\
\text { material } 2\end{array}$ & 158 & 160 & 56 & & 4 & 72 & & 96 & 68 & 70 & 100 & 56 & 50 & 76 & 62 & 4 & 138 & 108 & & \\
\hline
\end{tabular}

Table VI: The schedule of materials.

\begin{tabular}{|c|c|c|c|c|c|c|c|c|c|c|c|}
\hline \multirow{2}{*}{$\begin{array}{c}\text { Name of } \\
\text { material }\end{array}$} & \multicolumn{10}{|c|}{ Phase } & \multirow{2}{*}{ Total } \\
\cline { 2 - 13 }$n$ & 1 & 2 & 3 & 4 & 5 & 6 & 7 & 8 & 9 & 10 & \\
\hline Raw material 1 & & 424 & 176 & 128 & 184 & 208 & 168 & 312 & 104 & 82 & 1704 \\
\hline Raw material 2 & 424 & 176 & 128 & 184 & 208 & 168 & 312 & 104 & & 80 & 1704 \\
\hline Raw material 3 & 368 & 172 & 136 & 111 & 196 & 212 & 126 & 146 & 246 & & 1713 \\
\hline Raw material 4 & & 100 & 232 & 120 & 30 & 116 & 112 & & 160 & & 870 \\
\hline
\end{tabular}

Table VII: Using of resource and schedule of overtime work.

\begin{tabular}{|l|c|c|c|c|c|c|c|c|c|c|c|}
\hline & \multicolumn{7}{|c|}{ Phase } & \multirow{2}{*}{ Total } \\
\cline { 2 - 15 } & 1 & 2 & 3 & 4 & 5 & 6 & 7 & 8 & 9 & 10 & \\
\hline Resource 1 & 7.9 & 8 & 8 & 8 & 8 & 8.05 & 8 & 8 & 8 & 8 & 79.95 \\
\hline Resource 2 & 8 & 8 & 8 & 8 & 8.1 & 8 & 8 & 8 & 8 & 0.2 & 72.3 \\
\hline Overtime work of resource 1 & & & & & & 0.05 & & & & & 0.05 \\
\hline Overtime work of resource 2 & & & & & 0.1 & & & & & & 0.1 \\
\hline
\end{tabular}


Table VIII: Average inventory.

\begin{tabular}{|l|c|c|c|c|c|c|c|c|c|c|c|}
\hline \multirow{2}{*}{$\begin{array}{c}\text { Name of } \\
\text { material }\end{array}$} & \multicolumn{7}{|c|}{ Phase } & \multirow{2}{*}{ Total } \\
\cline { 2 - 13 } & 1 & 2 & 3 & 4 & 5 & 6 & 7 & 8 & 9 & 10 & \\
\hline Product 1 & 20 & 20 & 43 & 55.5 & 48.5 & 45 & 39 & 43.5 & 25.5 & 2 & 342 \\
\hline Product 2 & & & & & & & & 13 & 13 & & 26 \\
\hline Intermediate material 1 & & & & & & & & 56 & 56 & & 112 \\
\hline Intermediate material 2 & 159 & 187 & 28 & & & & & & & & 230 \\
\hline
\end{tabular}

From the results above, we can know that all products can be delivered on time. The overtime of work is small ( 0.15 hours), among which 0.1 hours for resource 2 and 0.05 hours for resource 1 . The overtime work is in phase 5 and phase 6 . The inventory of products and intermediate materials is large.

(2) Considering delivery on-time, overtime costs and inventory levels by priority

Set $M C_{t i}=10000, I C_{t i}=1000, R C_{t r}=1, S C_{t r}=0$, then optimize the schedule by the model, get that: $Z R N M=0, Z O C U=22, Z A I L=5000$. The detailed information is shown in Table IX to Table XII.

Table IX: The production schedule of products and intermediate materials related to every resource.

\begin{tabular}{|c|c|c|c|c|c|c|c|c|c|c|c|c|c|c|c|c|c|c|c|c|}
\hline \multirow{4}{*}{$\begin{array}{l}\text { Name of } \\
\text { material }\end{array}$} & \multicolumn{20}{|c|}{ Phase } \\
\hline & \multicolumn{2}{|c|}{1} & \multicolumn{2}{|c|}{2} & \multicolumn{2}{|c|}{3} & \multicolumn{2}{|c|}{4} & \multicolumn{2}{|c|}{5} & \multicolumn{2}{|c|}{6} & \multicolumn{2}{|r|}{7} & \multicolumn{2}{|c|}{8} & \multicolumn{2}{|c|}{9} & \multicolumn{2}{|c|}{10} \\
\hline & \multicolumn{2}{|c|}{ resource } & \multicolumn{2}{|c|}{ resource } & \multicolumn{2}{|c|}{ resource } & \multicolumn{2}{|c|}{ resource } & \multicolumn{2}{|c|}{ resource } & \multicolumn{2}{|c|}{ resource } & \multicolumn{2}{|c|}{ resource } & \multicolumn{2}{|c|}{ resource } & \multicolumn{2}{|c|}{ resource } & \multicolumn{2}{|c|}{ resource } \\
\hline & 1 & 2 & 1 & 2 & 1 & 2 & 1 & 2 & 1 & 2 & 1 & 2 & 1 & 2 & 1 & 2 & 1 & 2 & 1 & 2 \\
\hline Product 1 & & & & & 40 & & 65 & & 25 & & 60 & & 43 & 7 & 35 & & 65 & & 80 & 6 \\
\hline Product 2 & & & & & 50 & & 98 & 18 & 60 & & 15 & & 58 & & 30 & & 26 & & 80 & \\
\hline $\begin{array}{c}\text { Intermediate } \\
\text { material } 1\end{array}$ & & & 80 & & & 130 & & 50 & & 120 & & 100 & 29 & 41 & & 130 & & 172 & & \\
\hline $\begin{array}{c}\text { Intermediate } \\
\text { material } 2\end{array}$ & & & & 120 & 165 & 30 & 1 & 74 & 140 & 40 & 85 & 65 & & 105 & 165 & 30 & 229 & 29 & & \\
\hline
\end{tabular}

Table X: The schedule of materials.

\begin{tabular}{|c|c|c|c|c|c|c|c|c|c|c|c|}
\hline \multirow{2}{*}{$\begin{array}{c}\text { Name of } \\
\text { material }\end{array}$} & \multicolumn{10}{|c|}{ Phase } & \multirow{2}{*}{ Total } \\
\cline { 2 - 12 } & 1 & 2 & 3 & 4 & 5 & 6 & 7 & 8 & 9 & 10 & \\
\hline Raw material 1 & & 160 & 260 & 100 & 240 & 200 & 140 & 260 & 344 & & 1704 \\
\hline Raw material 2 & 160 & 260 & 100 & 240 & 200 & 140 & 260 & 344 & & & 1704 \\
\hline Raw material 3 & 50 & 236 & 255 & 90 & 238 & 180 & 131 & 275 & 258 & & 1713 \\
\hline Raw material 4 & & 100 & 232 & 120 & 30 & 116 & 60 & 52 & 160 & & 870 \\
\hline
\end{tabular}

Table XI: Using of resource and schedule of overtime work.

\begin{tabular}{|l|c|c|c|c|c|c|c|c|c|c|c|}
\hline & \multicolumn{10}{|c|}{ Phase } & \multirow{2}{*}{ Total } \\
\cline { 2 - 16 } & 1 & 2 & 3 & 4 & 5 & 6 & 7 & 8 & 9 & 10 & \\
\hline Resource 1 & 0 & 8 & 12.75 & 8.2 & 11.25 & 8 & 7.95 & 11.5 & 16 & 8 & 91.65 \\
\hline Resource 2 & 0 & 6 & 8 & 8 & 8 & 8.25 & 8 & 8 & 10.05 & 0.6 & 64.9 \\
\hline Overtime work of resource 1 & & & 4.75 & 0.2 & 3.25 & & & 3.5 & 8 & & 19.7 \\
\hline Overtime work of resource 2 & & & & & & 0.25 & & & 2.05 & & 2.3 \\
\hline
\end{tabular}


Table XII: Average inventory.

\begin{tabular}{|l|c|c|c|c|c|c|c|c|c|c|c|}
\hline \multirow{2}{*}{$\begin{array}{c}\text { Name of } \\
\text { material }\end{array}$} & \multicolumn{7}{|c|}{ Phase } & \multirow{2}{*}{ Total } \\
\cline { 2 - 12 } & 1 & 2 & 3 & 4 & 5 & 6 & 7 & 8 & 9 & 10 & \\
\hline Product 1 & 20 & 20 & 10 & & & & & & & & 50 \\
\hline Product 2 & & & & & & & & & & & \\
\hline Intermediate material 1 & & & & & & & & & & & \\
\hline Intermediate material 2 & & & & & & & & & & & \\
\hline
\end{tabular}

The results show that all products can be delivered on time. The inventory is small, and only product 1 has inventory in phase 1 , phase 2 and phase 3 with inventory $20,20,10$. The total overtime of work is 22 hours, among which 19.7 hours for resource 1 and 2.3 hours for resource 2 .

The comparison of overtime work and inventory between the two different cases is shown in Figs. 2 and 3.
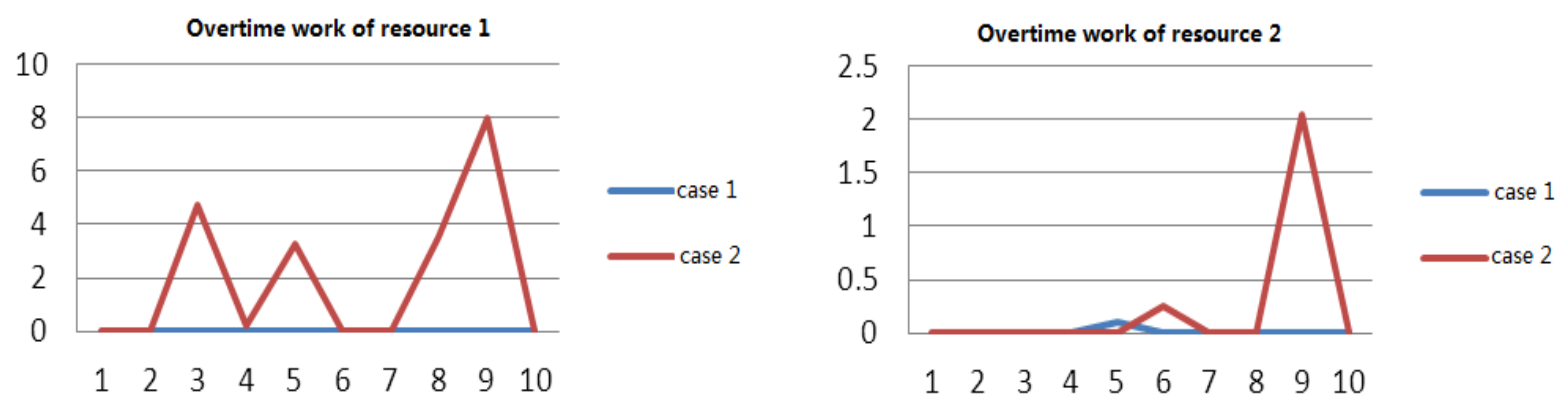

Figure 2: Comparison of overtime work between the two cases.

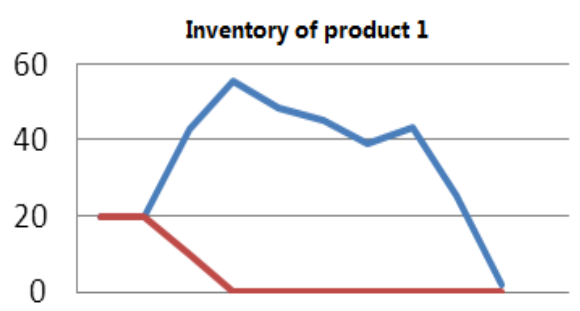

$\begin{array}{lllllllllll}1 & 2 & 3 & 4 & 5 & 6 & 7 & 8 & 9 & 10\end{array}$

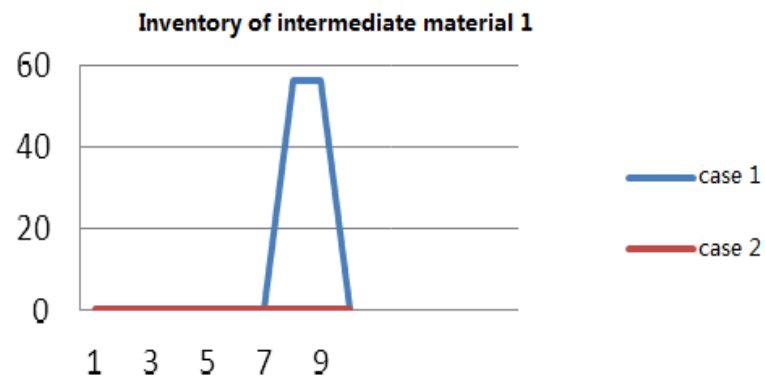

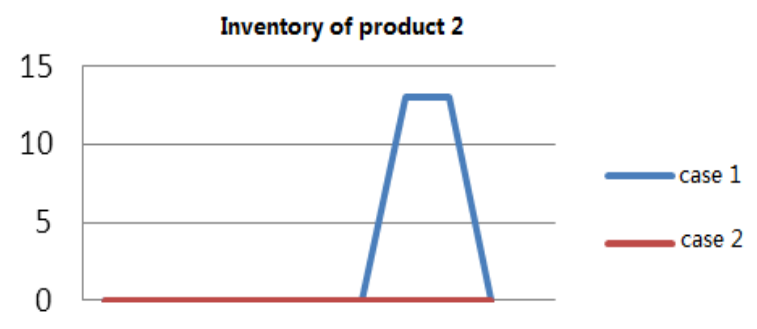

$\begin{array}{lllllllllll}1 & 2 & 3 & 4 & 5 & 6 & 7 & 8 & 9 & 10\end{array}$

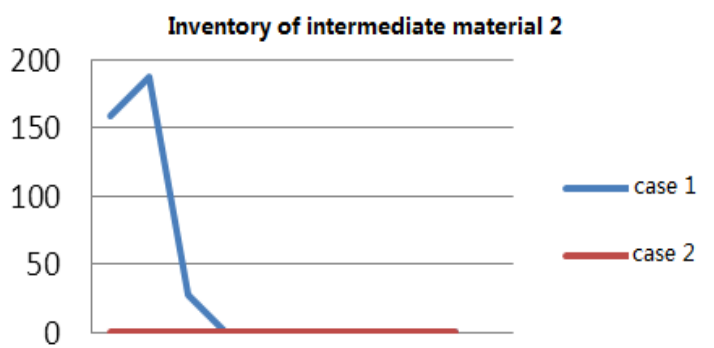

$123 \quad 3 \quad 4 \quad 5 \quad 6 \quad 7 \quad 8 \quad 910$

Figure 3: Comparison of products and intermediate materials inventory.

Through the comparison, it could be known that the inventory of case 2 is much smaller than that of case 1, but the overtime work is much more than that of case 1 . In the manufacturing process of products, the various objectives of the manufacturing process restrain each other mutually. The managers of enterprises can keep their minds focused on 
different management objectives by setting appropriate parameters to them. Also, the managers can calculate the cost parameters of different objectives according to the realistic condition or make decisions based on all the objectives.

According to different products, materials and resources, we also do the simulation analysis. We conducted four times simulation, and the effective results are all obtained by the optimization model. The test environment: Windows 7, $8 \mathrm{~GB}$ of memory, Intel core i7 processor, and the results are shown in Table XIII.

Table XIII: Results for different situations.

\begin{tabular}{|c|c|c|c|c|c|c|}
\hline ID & Production num & Max BOM Level & Material num & Resourse num & Phase & Running time \\
\hline 1 & 2 & 3 & 4 & 2 & 10 & 26 \\
\hline 2 & 5 & 3 & 10 & 4 & 10 & 245 \\
\hline 3 & 10 & 4 & 20 & 6 & 10 & 4431 \\
\hline 4 & 20 & 5 & 40 & 8 & 10 & 61250 \\
\hline
\end{tabular}

According to the above results, the optimization model proposed by this paper can get valid results under a certain scale of data.

\section{CONCLUSION}

As the principal function of enterprise, production planning is critical to the production business operation activities and cost control. In this paper, according to analysing the defects of ERP planning system and the existing relevant research results, we propose a multiobjective integrated production planning optimization model constrained by materials and resources doubly. The model not only considers the material and the capacity factor, but also takes into account the various performance management objectives of production process. It takes delivery on-time, reduce inventory, reduce overtime work, maintain safety inventory as its optimization objectives, and it can achieve the integrated optimization of production planning, material requirements planning, resource requirements planning, inventory planning and overtime work planning, through setting the cost parameters of objectives, it can choose or make a trade-off among the various objectives. Based on the multi-objective optimization model of integrated production planning above, we construct the following mixed integer programming model, and use Lingo 11.0 to complete the model solution and simulation analysis. The case analysis tells that the optimization methods provided by the model are able to support the manufacturing enterprises to make production plans and it has certain feasibility and effectiveness.

In this paper, we use the Lingo 11.0 to solve the mixed integer programming model. This solving method is only suitable for a certain scale of data, and more efficient algorithm needs to be studied for large-scale data. Moreover, considering more performance management objectives and constantly enhancing the practicability and applicability of the model is also one of the main directions of the future study.

\section{ACKNOWLEDGEMENTS}

This work was supported by Colleges of Heilongjiang Province Youth Academic backbone support program (1251G071), Heilongjiang Province Nature Science Fund, Heilongjiang Province Teaching Reform Project of Higher Education (JG2013010028). 


\section{REFERENCES}

[1] Tilokavichai, V.; Sophatsathit, P. (2011). An organization-wide analysis of ERP and information systems interrelationship for logistics support, Journal of System and Management Sciences, Vol. 1 , No. $1,70-81$

[2] Liu, X. (2009). The applied research on ERP implementation in Chinese enterprises, Modern Business, Vol. 27, 211+210

[3] Wang, C.; Liu, X.-B. (2013). Integrated production planning and control: A multi-objective optimization model, Journal of Industrial Engineering and Management, Vol. 6, No. 4, 815-830, doi:10.3926/jiem.771

[4] Hao, G.; Wu, G. (2005). Research on MRP of dynamic lot size \& lead-time based on daily output, Computer Integrated Manufacturing Systems, Vol. 11, No. 9, 1267-1271

[5] Jodlbauer, H.; Reitner, S. (2012). Material and capacity requirements planning with dynamic lead times, International Journal of Production Research, Vol. 50, No. 16, 4477-4492, doi:10.1080/00207543.2011.603707

[6] Cui, N. F.; Liu, Y. Z.; Yan, S. F. (2003) Improvement of lead time in MRP, Journal of Huazhong University of Science and Technology (Nature Science Edition), Vol. 31, No. 5, 95-97

[7] Memmi, I. C.; Laaroussi, S. H. (2013). A new approach for solving capacitated lot sizing and scheduling problem with sequence and period-dependent setup costs, Journal of Industrial Engineering and Management, Vol. 6, No. 4, 1027-1054, doi:10.3926/jiem.707

[8] Zhuang, Y. M.; He, J. M. (2002). An improved capacity requirements planning method for MRPII/ERP systems, Chinese Journal of Management Science, Vol. 10, No. 5, 62-68

[9] Huang, W.; Cai, L.; Hu, Y.; Wang, X.; Ling, L. (2009). Process planning optimization based on genetic algorithm and topological sort algorithm for digraph, Computer Integrated Manufacturing Systems, Vol. 15, No. 9, 1770-1778

[10] Liu, W.; Wang, T. Y.; Zhou, M.; Rao, J. (2010). Generation and optimization of process routing based on ant colony algorithm, Computer Integrated Manufacturing Systems, Vol. 16, No. 7, $1378-1382$

[11] Chen, J. H.; Peng, H. G. (2005). Integrated production planning and controlling model of MRPII, JIT and TOC in time-based competition, Industrial Engineering Journal, Vol. 8, No. 2, 66-69+78

[12] Lan, B. X. (2004). Enterprise resource optimization and optimization model, Computer Integrated Manufacturing Systems, Vol. 10, No. 3, 241-251

[13] Xiao, Y.; Zhang, R.; Chang, W. (2010). Enterprise planning model based on bill of manufacturing, Systems Engineering - Theory \& Practice, Vol. 30, No. 2, 227-235

[14] Kanet, J. J.; Stoslein, M. (2010). Integrating production planning and control: towards a simple model for Capacitated ERP, Production Planning \& Control, Vol. 21, No. 3, 286-300, doi:10.1080/09537280903363209

[15] Soares, M. M.; Vieira, G. E. (2009). A new multi-objective optimization method for master production scheduling problems based on genetic algorithm, International Journal of Advanced Manufacturing Technology, Vol. 41, No. 5-6, 549-567, doi:10.1007/s00170-008-1481-x

[16] Jia, W.; Liao, X.; Wang, M.; Shen, Y. (2002). Aggregate production planning with multiobjective in uncertain environment, Systems Engineering, Vol. 20, No. 5, 50-54

[17] Chen, Z. (2001). Flexible decision of MPS in MRPII system, Journal of Systems Engineering, Vol. 16, No. 6, 465-470

[18] Smith, N. R.; Robles, J. L.; Cardenas-Barron, L. E. (2009). Optimal pricing and production master planning in a multiperiod horizon considering capacity and inventory constraints, Mathematical Problems in Engineering, Vol. 2009, Article ID 932676, 15 pages, doi:10.1155/2009/932676 